\title{
Specific sagittal alignment patterns are already present in mild adolescent idiopathic scoliosis
}

\author{
Tom P. C. Schlösser ${ }^{1}$ (D) $\cdot$ René M. Castelein ${ }^{1} \cdot$ Pierre Grobost $^{2} \cdot$ Suken A. Shah ${ }^{3} \cdot$ Kariman Abelin-Genevois $^{2}$
}

Received: 26 July 2020 / Revised: 26 July 2020 / Accepted: 13 February 2021 / Published online: 27 February 2021

(C) The Author(s) 2021

\begin{abstract}
Purpose The complex three-dimensional spinal deformity in AIS consists of rotated, lordotic apical areas and neutral junctional zones that modify the spine's sagittal profile. Recently, three specific patterns of thoracic sagittal 'malalignment' were described for severe AIS. The aim of this study is to define whether specific patterns of pathological sagittal alignment are already present in mild AIS.

Methods Lateral spinal radiographs of 192 mild $\left(10^{\circ}-20^{\circ}\right)$ and 253 severe $\left(>45^{\circ}\right)$ AIS patients and 156 controls were derived from an international consortium. Kyphosis characteristics (T4-T12 thoracic kyphosis, T10-L2 angle, C7 slope, location of the apex of kyphosis and of the inflection point) and sagittal curve types according to Abelin-Genevois were systematically compared between the three cohorts.

Results Even in mild thoracic AIS, already $49 \%$ of the curves presented sagittal malalignment, mostly thoracic hypokyphosis, whereas only $13 \%$ of the (thoraco) lumbar curves and $6 \%$ of the nonscoliosis adolescents were hypokyphotic. In severe AIS, 63\% had a sagittal malalignment. Hypokyphosis + thoracolumbar kyphosis occurred more frequently in high-PI and primary lumbar curves, whereas cervicothoracic kyphosis occurred more in double thoracic curves.

Conclusions Pathological sagittal patterns are often already present in curves $10^{\circ}-20^{\circ}$, whereas those are rare in non-scoliotic adolescents. This suggests that sagittal 'malalignment' patterns are an integral part of the early pathogenesis of AIS.
\end{abstract}

Keywords Adolescent idiopathic scoliosis $\cdot$ Sagittal alignment $\cdot$ Hypokyphosis $\cdot$ Pathogenesis

\section{Introduction}

Tom P. C. Schlösser

t.p.c.schlosser@umcutrecht.nl

René M. Castelein

r.m.castelein@umcutrecht.nl

Pierre Grobost

pierre.grobost@gmail.com

Suken A. Shah

suken.shah@nemours.org

Kariman Abelin-Genevois

kgenevois@gmail.com

1 Department of Orthopaedic Surgery, G05.228, University Medical Center Utrecht, P.O. Box 85500, 3508 GA Utrecht, The Netherlands

2 Orthopaedic Department, Centre Medico Chirurgical Les Massues Croix Rouge Française, Lyon, France

3 Department of Orthopaedic Surgery, Nemours/Alfred I. duPont Hospital for Children, Wilmington, DE, USA
Adolescent idiopathic scoliosis (AIS) is a deformity of the spine and trunk that primarily affects previously healthy children, predominantly girls, during the growth spurt [1]. The fact that AIS is a complex 3-D deformity of the spine, rather than a simple lateral curvature, has been well appreciated for a long time [2-5]. The spinal deformity in AIS is the complex and sum of three variable spatial displacements in the apical region: In the coronal plane, it is characterized by lateral deviation and lateral bending, in the transverse plane by axial rotation and in the sagittal plane by extension of the spine.

While it was already known that severe AIS often leads to flattening of the thoracic spine, recent 3-D imaging studies showed that all severe AIS curves, primary as well as compensatory, are characterized by a segmental lordosis around the apex [6-8]. As a consequence, the regional thoracic kyphosis is modified by the rotated, lordotic apical areas and neutral junctional zones. In this, 
Abelin-Genevois et al. described four specific patterns of the presentation of the sagittal spinal profile on lateral radiographs: normal kyphosis (pattern 1), hypokyphosis (pattern 2a), hypokyphosis in combination with thoracolumbar kyphosis (pattern 2b), cervicothoracic kyphosis (pattern 3) (Fig. 1) [9].

In order to improve our understanding of the sequence in which the different aspects of the regional 3D deformity develop, the aim of this study was to define whether pathological sagittal patterns are already present in the earliest phase of the adolescent idiopathic scoliosis. Since radiographs before the onset of AIS are not widely available, for this study, we approach as closely as possible the starting point of AIS by cross-sectionally studying the sagittal patterns of the spine in adolescents with mild $\left(10^{\circ}-20^{\circ}\right)$ AIS, and compare this to adolescents with severe and without AIS.

Fig. 1 Abelin-Genevois classification, a system that differentiates four specific patterns of sagittal alignment in AIS $[9,12]$

\section{Materials and methods}

\section{Study population}

Following local institutional review board approval, patient databases at three centers specialized in scoliosis treatment in the USA, France and the Netherlands were systematically searched for standing posterior-anterior and lateral radiographs. For the mild AIS cohort, all cases with idiopathic scoliosis who had standard radiographs showing either a single thoracic or a single (thoraco) lumbar curve between $10^{\circ}$ and $20^{\circ}$ were included in this study. The mild AIS group was further classified into a primary thoracic and primary (thoraco) lumbar subgroup, since bending radiographs were not systematically available in this non-operative group to further classify according to Lenke. Patients were divided into three cohorts for cross-sectional comparisons. For the severe AIS cohort, pre-operative radiographs of a consecutive series of cases that were planned for AIS surgery and
Type 1: Normal kyphosis

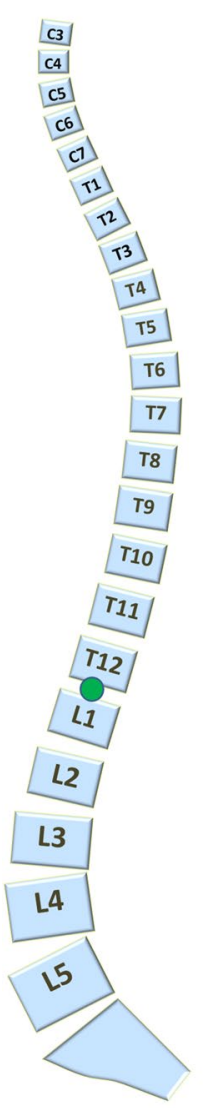

Type 2a: Hypokyphosis

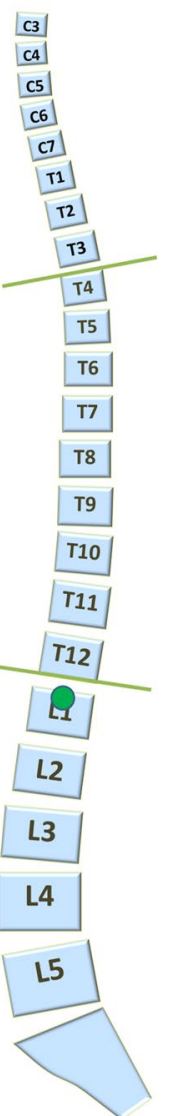

Type 2b: Hypokyphosis + thoracolumbar kyphosis

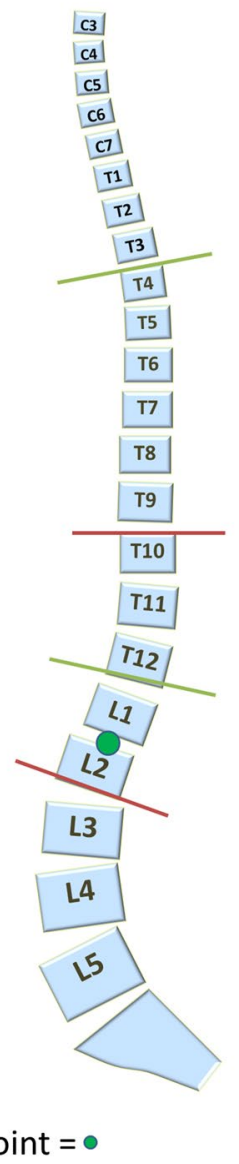

Type 3:

Cervicothoracic kyphosis

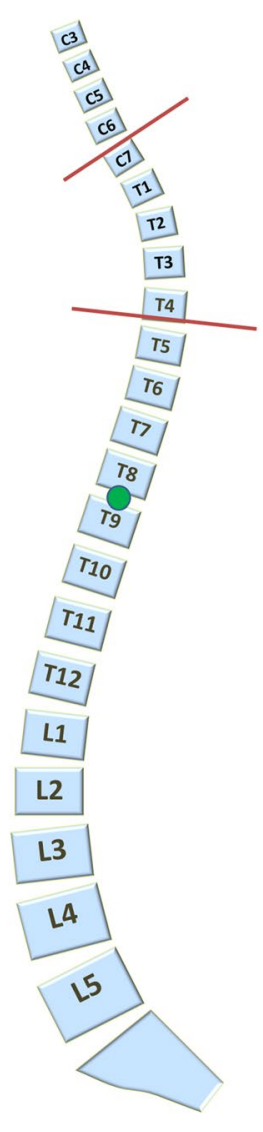


had a major coronal curve angle $>45^{\circ}$ were used. Databases were previously collected for systematic study of the surgical outcomes in each center separately. For the cohort of nonscoliotic controls, we used an existing cohort of children between 7 and 18 years old that had undergone standing posterior-anterior and lateral radiological screening for scoliosis, but had no significant spinal asymmetry at the initial radiograph taken or at follow-up $[10,11]$.

Similar protocols for radiographic acquisition of digital, plain, full-length lateral radiographs were used in the three centers. Acquisition was performed in an upright standing position, subjects were standing with their hips and knees straight, and they were instructed to stand in a comfortable manner and to look straight ahead with the hand on the zygoma's or on the clavicles. Radiographs from outside facilities or on which the whole spine and both femoral heads were not clearly identifiable were excluded.

\section{Radiographic analyses}

Two trained observers measured conventional parameters describing (parts of) the magnitudes of sagittal thoracic morphology using Surgimap ${ }^{\circledR}$ (Nemaris Inc. ${ }^{\mathrm{TM}}$, New York, NY, USA). Next, they classified each spine according to the Abelin-Genevois sagittal curve patterns and kyphosis characteristics (level of the inflection point and level of the apex of the thoracic kyphosis) (Figs. 1 and 2) [9, 12]. For demographical comparison and final comparison of the discriminative parameters between different sagittal patterns, also pelvic incidence, pelvic tilt, sacral slope, Roussouly lumbosacral type and L1-S1 lumbar lordosis were measured [13].

\section{Statistical analysis}

The statistical analyses were performed using statistical software SPSS 23 for Windows (SPSS Inc., Chicago, IL, USA). Descriptive statistics were computed for the cohorts, providing means and standard deviations for continuous data, and frequencies and percentages for nominal data. The epidemiology of normokyphosis (pattern 1) and pathological (patterns 2a, 2b and 3) sagittal alignment in AIS patients and non-scoliotic adolescents were compared using FisherFreeman-Halton tests in the analysis of contingency tables. Comparison of sagittal parameters between scoliosis with different severity (mild primary thoracic AIS, mild primary (thoraco) lumbar AIS, severe primary thoracic AIS, severe primary (thoraco) lumbar AIS) was performed using oneway ANOVA. Potential parameters differentiating different Abelin-Genevois curve patterns were evaluated using one-way ANOVA. A Bonferroni correction was applied for multiple testing. The level of statistical significance was set at $P<0.05$.

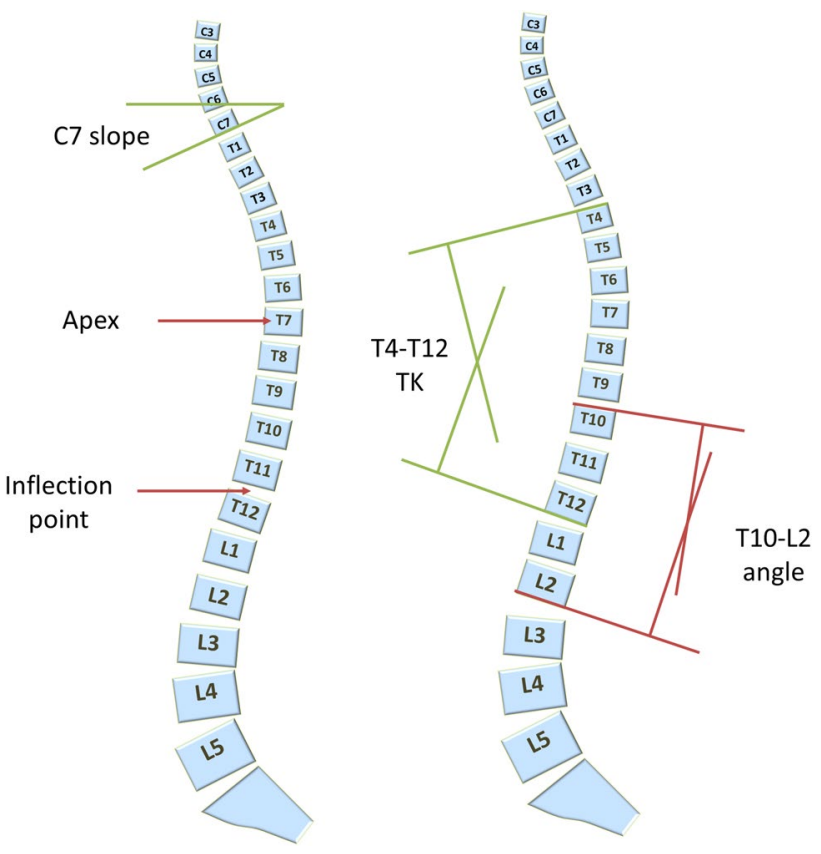

Fig. 2 Outcome parameters were the level of the inflection point (where the lumbar lordosis changes into the thoracic kyphosis), apex of the thoracic kyphosis (the vertebra with the farthest posterior deviation from the C7 plumb line), C7 slope, T4-T12 thoracic kyphosis and $\mathrm{T} 10-\mathrm{L} 2$ thoracolumbar angle

\section{Results}

192 mild AIS and 253 severe AIS patients and 156 nonscoliotic controls were available for inclusion in this study. Demographics are shown in Table 1. Epidemiological analysis of sagittal patterns according Abelin-Genevois classification revealed significant differences between the mild AIS, severe AIS and control group $(P=0.003$; Table 2$)$. In the non-scoliotic adolescents, $91 \%$ had a normokyphosis in terms of length, magnitude and apex. Of the 192 mild AIS cases, $41 \%$ (35\% pattern $2 \mathrm{a}, 5 \%$ pattern $2 \mathrm{~b}$ and $1 \%$ pattern 3 ) were classified as a pathological sagittal pattern and 59\% as normokyphosis (pattern 1). In severe AIS, $56 \%$ of the 256 subjects showed a pathological sagittal pattern: $38 \%$ pattern $2 \mathrm{a}, 8 \%$ pattern $2 \mathrm{~b}$ and $10 \%$ pattern 3 . Subgroup analysis according to Lenke type revealed significant differences in the prevalence of the different sagittal patterns $(P=0.001$, Tables 3 and 4).

\section{Discussion}

Deacon et al. described the lordotic effect of development of AIS on the thoracic sagittal spinal profile in 1984, and nowadays it is generally known that hypokyphosis is often an integral part of severe AIS [4]. Although the true 3-D morphology of the spine and hypokyphosis in severe AIS is well 
Table 1 Demographics

\begin{tabular}{|c|c|c|c|c|c|}
\hline & Mild AIS $(n=192)$ & Severe AIS $(n=253)$ & Controls $(n=156)$ & $\begin{array}{l}P \text { value mild versus } \\
\text { severe AIS }\end{array}$ & $\begin{array}{l}P \text { value AIS } \\
\text { versus con- } \\
\text { trols }\end{array}$ \\
\hline Age in years, mean $\pm s d$ & $13.2 \pm 1.8$ & $14.7 \pm 1.8$ & $12.0 \pm 2.3$ & $<0.001$ & $<0.001$ \\
\hline Girls, $n(\%)$ & $143(75)$ & $215(85)$ & $99(62)$ & $<0.001$ & $<0.001$ \\
\hline Major curve angle \pm sd & $15 \pm 3$ & $58 \pm 15$ & - & $<0.001$ & Not applicable \\
\hline $\mathrm{PI}$, mean $\pm \mathrm{sd}$ & $46 \pm 11$ & $50 \pm 12$ & $44 \pm 12$ & $<0.001$ & $<0.001$ \\
\hline $\mathrm{PT}$ & $7 \pm 9$ & $8 \pm 8$ & $5 \pm 8$ & 0.21 & $<0.001$ \\
\hline SS & $38 \pm 8$ & $42 \pm 9$ & $38 \pm 9$ & $<0.001$ & $<0.001$ \\
\hline Roussouly type & & & & $<0.001$ & $<0.001$ \\
\hline $1, n(\%)$ & $13(7)$ & $14(6)$ & $11(7)$ & & \\
\hline 2 & $42(22)$ & $47(19)$ & $42(27)$ & & \\
\hline 3 & $64(33)$ & $64(25)$ & $40(26)$ & & \\
\hline $3-\mathrm{AV}$ & $41(21)$ & 47 (19) & $32(21)$ & & \\
\hline 4 & 32 (17) & $81(32)$ & $31(20)$ & & \\
\hline
\end{tabular}

Table 2 Distribution of pathological (types $2 \mathrm{a}, 2 \mathrm{~b}$ and 3 ) sagittal alignment and normokyphosis (type 1) in AIS patients and non-scoliotic adolescents

\begin{tabular}{|c|c|c|c|c|c|c|}
\hline & $n$ & $\begin{array}{l}\text { Type } 1 \text { (nor- } \\
\text { mokyphosis) }\end{array}$ & $\begin{array}{l}\text { Type 2a } \\
\text { (hypokyphosis) }\end{array}$ & $\begin{array}{l}\text { Type } 2 \text { b (hypokypho- } \\
\text { sis + thoracolumbar kyphosis) }\end{array}$ & $\begin{array}{l}\text { Type } 3 \text { (cervicotho- } \\
\text { racic kyphosis) }\end{array}$ & $P$ \\
\hline Mild AIS, n (\%) & 192 & $113(59)$ & $67(35)$ & $10(5)$ & $2(1)$ & $<.01$ \\
\hline Thoracic & 128 & $58(45)$ & $63(49)$ & $5(4)$ & $2(2)$ & \\
\hline (Thoraco) lumbar & 64 & $55(86)$ & $4(6)$ & $5(8)$ & $0(0)$ & \\
\hline Severe AIS & 253 & $112(44)$ & $95(38)$ & $20(8)$ & $26(10)$ & 0.001 \\
\hline Lenke 1 & 111 & 43 (39) & $56(50)$ & $2(2)$ & $10(9)$ & \\
\hline Lenke 2 & 41 & $14(34)$ & $13(32)$ & $2(5)$ & $12(29)$ & \\
\hline Lenke $3 / 4$ & 42 & $24(57)$ & $12(29)$ & $5(12)$ & $1(2)$ & \\
\hline Lenke 5/6 & 59 & $31(53)$ & $14(24)$ & $11(19)$ & $3(5)$ & \\
\hline Non-scoliotic adolescents & 156 & 147 (94) & $6(4)$ & $2(1)$ & $1(1)$ & 0.45 \\
\hline
\end{tabular}

Table 3 Sagittal parameters describing sagittal thoracic morphology and magnitude in 192 mild and 253 severe AIS patients

\begin{tabular}{|c|c|c|c|c|c|c|}
\hline & $\begin{array}{l}\text { Mild AIS, lenke } \\
1(n=128)\end{array}$ & $\begin{array}{l}\text { Mild AIS, } \\
\text { lenke } 5(n=64)\end{array}$ & $\begin{array}{l}\text { Severe AIS lenke } \\
1-4(n=194)\end{array}$ & $\begin{array}{l}\text { Severe AIS lenke } \\
5-6(n=59)\end{array}$ & $\begin{array}{l}\text { Non-scoliotic ado- } \\
\text { lescent }(n=156)\end{array}$ & $P$ \\
\hline $\mathrm{T} 4-\mathrm{T} 12 \mathrm{TK}$ & $28 \pm 8 * \dagger$ & $42 \pm 8 \dagger$ & $20 \pm 14 \dagger$ & $22 \pm 15 \dagger$ & $33 \pm 10$ & $<.001$ \\
\hline $\begin{array}{l}\text { Number of lordotic vertebrae in the } \\
\text { lumbar area (inflection point) }\end{array}$ & $5.0 \pm 1.0$ & $4.8 \pm 0.9$ & $5.3 \pm 1.4^{* \dagger}$ & $4.6 \pm 1.1$ & $4.7 \pm 0.9$ & $<.001$ \\
\hline Level of apex of TK median (mean) & $\mathrm{T} 6(5.89)^{*} \dagger$ & $\mathrm{T} 8(7.73) \dagger$ & $\mathrm{T} 7(6.66)$ & $\mathrm{T} 8(7.07)$ & $\mathrm{T} 7(6.88)$ & $<.001$ \\
\hline C7-slope & $19 \pm 8^{*}$ & $24 \pm 10$ & $17 \pm 11 \dagger$ & $19 \pm 11$ & $21 \pm 9$ & $<.001$ \\
\hline T10-L2 thoracolumbar junction angle & $1.7 \pm 8^{*}$ & $6.7 \pm 10$ & $-1.7 \pm 10^{*} \dagger$ & $5.0 \pm 11$ & $3.2 \pm 4$ & $<.001$ \\
\hline
\end{tabular}

$*=$ Lenke 1 vs 5

$\dagger=$ vs control

described, the phases in which the sagittal profile changes during the development of the deformity occur are important both for better understanding the patho-mechanism as well as for daily orthopedic practice and conservative treatment.
Over the last decade, it became clear that the thoracic lordosis in AIS curves is not a global, but rather a regional phenomenon in the apical disks of the primary as well as secondary curves $[6,7,14]$. Development of this local 3-D 
Table 4 Factors differentiating Abelin-Genevois curve types

\begin{tabular}{|c|c|c|c|c|c|}
\hline & $\begin{array}{l}\text { Abelin- } \\
\text { Genevois } \\
\text { type } 1 \\
(n=372)\end{array}$ & $\begin{array}{l}\text { Abelin- } \\
\text { Genevois type } \\
2 \mathrm{a} \\
(n=168)\end{array}$ & $\begin{array}{l}\text { Abelin- } \\
\text { Genevois type } \\
2 \mathrm{~b} \\
(n=32)\end{array}$ & $\begin{array}{l}\text { Abelin-Genevois type } 3 \\
(n=29)\end{array}$ & $P$ \\
\hline T4-T12 TK & $34 \pm 10$ & $16 \pm 10$ & $22 \pm 13$ & $18 \pm 15$ & $<.001^{*}$ \\
\hline L1-S1 LL & $-52 \pm 13$ & $-51 \pm 11$ & $-48 \pm 13$ & $-52 \pm 12$ & 0.50 \\
\hline PI & $45 \pm 12$ & $50 \pm 12$ & $45 \pm 12$ & $50 \pm 11$ & $<.001^{*}$ \\
\hline PT & $6 \pm 9$ & $9 \pm 8$ & $8 \pm 6$ & $8 \pm 7$ & $.002 *$ \\
\hline SS & $39 \pm 9$ & $41 \pm 9$ & $36 \pm 10$ & $42 \pm 9$ & $.004 *$ \\
\hline Number of lordotic vertebrae (inflection point) & $4.8 \pm 0.9$ & $5.1 \pm 1.2$ & $4.1 \pm 0.9$ & $6.8 \pm 1.6$ & $<.001^{*}$ \\
\hline $\begin{array}{l}\text { Mean level of apex of TK } \\
\text { median }\end{array}$ & $7.0 \pm 1.3$ & $6.1 \pm 1.5$ & $8.0 \pm 2.0$ & $5.5 \pm 1.6$ & $<.001^{*}$ \\
\hline C7-slope & $22.2 \pm 9.6$ & $16.8 \pm 8.2$ & $14.4 \pm 9.5$ & $20.1 \pm 10.0$ & $<.001^{*}$ \\
\hline T10-L2 thoracolumbar junction angle & $2.4 \pm 7.8$ & $-0.2 \pm 7.6$ & $16.0 \pm 8.8$ & $-8.9 \pm 10.0$ & $<.001^{*}$ \\
\hline
\end{tabular}

deformation will mostly modify the morphology and magnitude of the thoracic kyphosis and thoracolumbar junction. Abelin-Genevois et al. demonstrated four specific patterns of sagittal alignment in severe AIS (Fig. 1) [9]. They described the regional modifications of the presentation of the thoracic profile on lateral radiographs (thus the global mid-sagittal plane), including the thoracolumbar and cervicothoracic junction, as opposed to segmental 3-D morphological changes (segmental sagittal plane) that were the subject of previous studies [6, 7]. Likewise, Pasha et al. recently performed cluster analyses on coronal and sagittal spinal alignment parameters in 103 right thoracic AIS curves and identified five different subtypes of 3-D global spinal shape, on which their innovative 3D classification is based $[15,16]$.

In the present study, we analyzed the regional modifications of the presentation of the thoracic sagittal profile on lateral radiographs of mild AIS $\left(10^{\circ}-20^{\circ}\right)$ and compared this to severe AIS and non-scoliotic adolescents. Interestingly, in mild thoracic AIS, already $49 \%$ of the spines presented with a thoracic hypokyphosis (pattern $2 \mathrm{a}$ ). On the contrary, only $13 \%$ of (thoraco) lumbar curves and $6 \%$ of the non-scoliotic adolescents had a pathological sagittal pattern. Since the pathological patterns were rare in the non-scoliotics, we do not consider the younger age and gender differences in the controls as a confounding factor for these findings. Similar to the literature, $63 \%$ of the severe thoracic AIS had a pathological sagittal profile: Hypokyphosis (pattern 2a) was the most prevalent curve pattern, hypokyphosis + thoracolumbar kyphosis (pattern 2b) occurred more frequently in high-PI and primary lumbar curves, whereas cervicothoracic kyphosis (pattern 3) occurred more in double thoracic curves [9, 17].

Many previous studies demonstrated the regional flattening of the thoracic sagittal profile on lateral radiographs, as a result of the rotated apical lordosis [18-20]. Not all thoracic spines in AIS, however, present as a hypokyphosis on lateral radiographs. It must be understood that due to the rotation, a regional kyphosis can still exist between $\mathrm{T} 1$ and $\mathrm{T} 12$, whereas at the segmental level, all vertebrae in between the end vertebrae are in a rotated lordosis. Sullivan et al. previously pointed out that some spines appear kyphotic on a lateral radiograph, when in fact they are rotated and lordotic segmentally. They also demonstrated that as the coronal curve becomes more severe, the lateral radiograph to measure segmental kyphosis becomes less accurate [21]. Clément et al. noted that approximately half of the primary thoracic curves present as a normokyphosis on lateral radiographs when the regional kyphosis is considered [19]. Also, Pizones et al. demonstrated patients with severe AIS were on average more hypokyphotic than healthy adolescents and that double thoracic curves were associated with a high thoracic kyphosis [20]. In many previous studies, however, only severe/preoperative AIS cases were included and the individual variability in concomitant coronal spinal deformation and sagittal alignment was not taken into account. Due to the significant heterogeneity of sagittal pelvic morphology and spino-pelvic alignment in the pediatric and adult population, as well as the differences in timing of the growth spurt between boys and girls and between individuals from the same gender, it can be assumed that the effect of the complex 3-D deformation on the regional spinal alignment and balance is almost unique for each AIS patient. Recently, Fruergaard et al. confirmed this heterogeneity of spino-pelvic parameters in this population by comparing sagittal parameters between the different Abelin-Genevois curve patterns [17].

Confirmation of previous findings from the literature on sagittal alignment in severe AIS and the high prevalence of pathological sagittal patterns in mild AIS raises the question whether AIS development can be attributed to the sagittal component of scoliosis. The variation in sagittal alignment of the spine is increasingly recognized in the etio-pathogenesis of different spinal deformities. According to the 
concept by Castelein et al., it can be inferred that the area of the spine in which a rotational deformity has a chance to develop is based on an individual's sagittal profile before the onset of the deformity [22]. They have shown that in the upright position, the vertebrae between the apex of thoracic kyphosis and lumbar lordosis are posteriorly tilted and therefore affected by posteriorly directed shear loads, reducing the rotational stability of those segments [10]. Since radiographs before the onset of AIS are normally not available, for this study, we tried to approach the starting point of AIS by cross-sectionally studying the sagittal patterns of the spine in adolescents with mild $\left(10^{\circ}-20^{\circ}\right)$ AIS. Based on the results of the present study, we can conclude that also in these mild curves, the distribution of sagittal patterns differs tremendously from controls. The question remains, however, whether even in mild coronal curves the sagittal profile is already affected by apical lordotic deformation. Of course, longitudinal studies following children from before the onset of AIS to severe AIS are required for definitive cause-andeffect conclusions. Such a study, however, seems practically and ethically very difficult to perform, using radiographs in asymptomatic children. Nonionizing 3-D spinal ultrasound seems a promising technique for those research questions that require prospective follow-up of pediatric spinal morphology, this is the topic of an ongoing study [23]. Based on the heterogeneity of sagittal patterns in the population of Fruergaard et al. and the present study, it would be recommended that also other factors that affect sagittal alignment, such as the individual changes of pelvic morphology during growth and BMI, are taken into account [17, 24].

The number of patients with severe AIS that is not normokyphotic (patterns $2 \mathrm{a}, 2 \mathrm{~b}$ or 3 ) is similar to patients with mild AIS (55\% in early AIS vs 43-66\% in the severe primary thoracic AIS group, respectively). This may also indicate a relation between the pre-existent sagittal pelvic morphology and the sagittal spinal deformation after the onset of AIS. The severity of the hypokyphosis, however, differed significantly between the patients with mild $\left(28^{\circ} \pm 8^{\circ}\right)$ and severe $\left(20^{\circ} \pm 14^{\circ}\right)$ primary thoracic AIS.

From this study follows that sagittal 'malalignment' is an integral part of mild and severe AIS and that also early treatment of mild AIS should ideally address the sagittal pathological patterns of the disease. The primary goal of definitive scoliosis surgery in severe AIS has always been to prevent progression, provide a balanced spine in the coronal and sagittal plane, fuse as few vertebrae as possible and avoid complications. There is evidence, however, that restoring as normal an anatomy as possible is beneficial to the remaining, unfused areas of the spine [25-27]. Even with modern day surgical techniques, it remains difficult, however, to really recreate the normal shape of the spine and avoid problems like thoracic hypokyphosis and junctional decompensation. For corrective scoliosis surgery, and also for conservative management, it is essential to have a thorough understanding of the deformity of the spine in all three dimensions, and the obstacles to reduction. When the distribution of pathological sagittal patterns was compared between mild and severe AIS, certain sagittal patterns occurred more in certain coronal curve types in the severe AIS cohort. For example, the pattern of cervicothoracic kyphosis was most frequently observed in severe double thoracic curves and the pattern $2 \mathrm{~b}$ pattern in patients with a structural main thoracic and (thoraco) lumbar curve. In addition to the aforementioned sagittal patterns that pre-exist, at least at the earliest phase of spinal deformation, from the results of this study, we can conclude that at severe spinal deformation, the sagittal patterns also represent the changes due to the pathologic effect of the local rotated lordosis at the apex of the corresponding structural, primary and secondary curves. Why similar coronal curves coincide with different sagittal patterns can likely be explained by the high heterogeneity of sagittal pelvic morphology and spino-pelvic alignment in the pediatric population. It may also serve as a differentiating phenotypical marker of the disease that could be a track to better drive the analysis of genetic susceptibility.

In conclusion, segmental lordotic deformation is, together with rotation and lateral deviation an integral part of the complex three-dimensional deformity in AIS. Classification of 192 mild, 253 severe AIS and 156 controls according to the recently introduced Abelin-Genevois classification showed that even in mild AIS, the sum of the pre-existent sagittal profile and the rotated apical and junctional zones often present as a pathological sagittal alignment. Since sagittal 'malalignment' is an integral part of the onset and early development of AIS, also at an early stage, treatment should include the sagittal pathological patterns of the disease.

\section{Funding None.}

\section{Compliance with ethical standard}

Conflict of interest Schlösser: no conflicts. Castelein: K2M (grants/research support, speaker's bureau). Grobost: no conflicts. Shah: DePuy Synthes (consultant, advisory board or panel, royalties); Globus Medical (other financial support (royalties, patents)); K2M (other financial support (royalties, patents, etc.); NuVasive (consultant). Abelin: Implanet (other financial support (royalties, patents)); Medicrea (consultant); Medtronic (speaker's bureau).

Open Access This article is licensed under a Creative Commons Attribution 4.0 International License, which permits use, sharing, adaptation, distribution and reproduction in any medium or format, as long as you give appropriate credit to the original author(s) and the source, provide a link to the Creative Commons licence, and indicate if changes were made. The images or other third party material in this article are included in the article's Creative Commons licence, unless indicated otherwise in a credit line to the material. If material is not included in 
the article's Creative Commons licence and your intended use is not permitted by statutory regulation or exceeds the permitted use, you will need to obtain permission directly from the copyright holder. To view a copy of this licence, visit http://creativecommons.org/licenses/by/4.0/.

\section{References}

1. Weinstein SL, Dolan LA, Cheng JC, Danielsson A, Morcuende JA (2008) Adolescent idiopathic scoliosis. Lancet 371:1527-1537. https://doi.org/10.1016/S0140-6736(08)60658-3

2. Nicoladoni C (1904) Anatomie und mechanismus der skoliose. In: kocher T, König P, von Mikulicz J, eds. Bibliotheca medica. edn. Verlag von Erwin Nagele, Stuttgart

3. Roaf R (1966) The basic anatomy of scoliosis. J Bone Jt Surg Br 48:786-792

4. Deacon P, Flood BM, Dickson RA (1984) Idiopathic scoliosis in three dimensions. A radiographic and morphometric analysis. J Bone Jt Surg Br 66:509-512

5. Dickson RA (1988) The aetiology of spinal deformities. Lancet 1:1151-1155

6. Schlösser TP, van Stralen M, Brink RC, Chu WC, Lam TP, Vincken KL et al (2014) Three-dimensional characterization of torsion and asymmetry of the intervertebral discs versus vertebral bodies in adolescent idiopathic scoliosis. Spine 39(19):E1159E1166. https://doi.org/10.1097/BRS.0000000000000467

7. Newton PO, Fujimori T, Doan J, Reighard FG, Bastrom TP, Misaghi A (2015) Defining the "three-dimensional sagittal plane" in thoracic adolescent idiopathic scoliosis. J Bone Jt Surg Am 97:1694-1701. https://doi.org/10.2106/JBJS.O.00148

8. Schlosser TP, van Stralen M, Chu WC, Lam TP, Ng BK, Vincken KL et al (2016) Anterior overgrowth in primary curves, compensatory curves and junctional segments in adolescent idiopathic scoliosis. PLoS One 11:e0160267. https://doi.org/10.1371/journ al.pone. 0160267

9. Abelin-Genevois K, Sassi D, Verdun S, Roussouly P (2018) Sagittal classification in adolescent idiopathic scoliosis: original description and therapeutic implications. Eur Spine J 27:21922202. https://doi.org/10.1007/s00586-018-5613-1

10. Schlosser TP, Vincken KL, Rogers K, Castelein RM, Shah SA (2015) Natural sagittal spino-pelvic alignment in boys and girls before, at and after the adolescent growth spurt. Eur Spine J 24(6):1158-1167. https://doi.org/10.1007/s00586-014-3536-z

11. Schlosser TP, Shah SA, Reichard SJ, Rogers K, Vincken KL, Castelein RM (2014) Differences in early sagittal plane alignment between thoracic and lumbar adolescent idiopathic scoliosis. Spine J 2:282-290

12. Post M, Verdun S, Roussouly P, Abelin-Genevois K (2019) New sagittal classification of AIS: validation by $3 \mathrm{D}$ characterization. Eur Spine J 28:551-558. https://doi.org/10.1007/s0058 6-018-5819-2

13. Laouissat F, Sebaaly A, Gehrchen M, Roussouly P (2018) Classification of normal sagittal spine alignment: refounding the Roussouly classification. Eur Spine J 27:2002-2011. https://doi. org/10.1007/s00586-017-5111-x

14. Schlosser TP, van Stralen M, Brink RC, Chu WC, Lam TP, Vincken KL et al (2014) Three-dimensional characterization of torsion and asymmetry of the intervertebral discs versus vertebral bodies in adolescent idiopathic scoliosis. Spine (Phila Pa 1976) 39(19):E1159-E1166. https://doi.org/10.1097/BRS.0000000000 000467
15. Pasha S, Flynn J (2018) Data-driven classification of the 3d spinal curve in adolescent idiopathic scoliosis with an applications in surgical outcome prediction. Sci Rep 8:16296-018-34261-6. https ://doi.org/10.1038/s41598-018-34261-6

16. Pasha S, Hassanzadeh P, Ecker M, Ho V (2019) A hierarchical classification of adolescent idiopathic scoliosis: identifying the distinguishing features in 3D spinal deformities. PLoS ONE 14:e0213406. https://doi.org/10.1371/journal.pone.0213406

17. Fruergaard S, Jain MJ, Deveza L, Liu D, Heydemann J, OhrtNissen S et al (2019) Evaluation of a new sagittal classification system in adolescent idiopathic scoliosis. Eur Spine J 29(4):744753. https://doi.org/10.1007/s00586-019-06241-5

18. Upasani VV, Tis J, Bastrom T, Pawelek J, Marks M, Lonner B et al (2007) Analysis of sagittal alignment in thoracic and thoracolumbar curves in adolescent idiopathic scoliosis: how do these two curve types differ? Spine 32(12):1355-1359

19. Clement JL, Geoffray A, Yagoubi F, Chau E, Solla F, Oborocianu I et al (2013) Relationship between thoracic hypokyphosis, lumbar lordosis and sagittal pelvic parameters in adolescent idiopathic scoliosis. Eur Spine J 22(11):2414-2420. https://doi.org/10.1007/ s00586-013-2852-z

20. Pizones J, Nunez-Medina A, Sanchez-Mariscal F, Zuniga L, Izquierdo E (2016) Thoracic sagittal plane variations between patients with thoracic adolescent idiopathic scoliosis and healthy adolescents. Eur Spine J 25:3095-3103. https://doi.org/10.1007/s0058 6-016-4400-0

21. Sullivan TB, Reighard FG, Osborn EJ, Parvaresh KC, Newton PO (2017) Thoracic idiopathic scoliosis severity is highly correlated with 3d measures of thoracic kyphosis. J Bone Jt Surg Am 99:e54. https://doi.org/10.2106/JBJS.16.01324

22. Castelein RM, van Dieen JH, Smit TH (2005) The role of dorsal shear forces in the pathogenesis of adolescent idiopathic scoliosis-a hypothesis. Med Hypotheses 65:501-508. https://doi. org/10.1016/j.mehy.2005.03.025

23. Lee TT, Jiang WW, Cheng CLK, Lai KK, To MKT, Castelein RM et al (2019) A novel method to measure the sagittal curvature in spinal deformities: the reliability and feasibility of 3-D ultrasound imaging. Ultrasound Med Biol 45(10):2725-2735

24. Valdovino AG, Bastrom TP, Reighard FG, Cross M, Bartley CE, Shah SA et al (2019) Obesity is associated with increased thoracic kyphosis in adolescent idiopathic scoliosis patients and nonscoliotic adolescents. Spine Deform 7(6):865-869

25. Akazawa T, Kotani T, Sakuma T, Minami S, Orita S, Fujimoto $\mathrm{K}$ et al (2017) Spinal fusion on adolescent idiopathic scoliosis patients with the level of L4 or lower can increase lumbar disc degeneration with sagittal imbalance 35 years after surgery. Spine Surg Relat Res 1:72-77. https://doi.org/10.22603/ ssrr.1.2016-0017

26. Ilharreborde B (2018) Sagittal balance and idiopathic scoliosis: does final sagittal alignment influence outcomes, degeneration rate or failure rate? Eur Spine J 27:48-58. https://doi.org/10.1007/ s00586-018-5472-9

27. Mimura T, Ikegami S, Oba H, Uehara M, Koseki M, Takahashi J (2019) Factors leading to postoperative pain in adolescent idiopathic scoliosis patients including sagittal alignment and lumbar disc degeneration. Eur Spine J 28:3085-3091. https://doi. org/10.1007/s00586-019-06152-5

Publisher's Note Springer Nature remains neutral with regard to jurisdictional claims in published maps and institutional affiliations. 